\section{Meetings and Courses}

Annual Courses

Title: Warwick Medical School Courses in Sexual and Reproductive Health. Details: See display advertisement on page 87 .

Annual Courses

Title: Courses in Sexual and Reproductive Health organised by The Sandyford Initiative. Details: See display advertisement on page 88 .

Annual Courses

Title: Courses on Current Issues in Sexual and Reproductive Health organised by The Margaret Pyke Memorial Trust. Details: See display advertisement on page 86 .

21-22 February 2005

Title: STIF Course. Venue: London, UK. Details: The aim is to equip doctors with the basic knowledge, skills and attitudes for the effective management of STIs. Accreditation: BASHH. Information: Grace Gray, Training Administrator, The Sexual \& Reproductive Health Training Partnership, Southwark PCT, St Giles Hospital, St Giles Road, London SE5 7RN, UK. Tel: +44 (0) 207771 3322. Fax: +44 (0) 2077713338 E-mail: srhtp@southwarkpct.nhs.uk.

5 March 2005

Title: Northern Interbranch Group Spring Update. Venue: The Lindhurst Rooms, Mansfield Civic Centre, Mansfield, UK. Details: A 1-day update meeting for members and guests on reproductive and sexual health. Topics to include: detection of infection, dysmenorrhoea management, understanding child sexual exploitation and recent changes in legislation, IUD and IUS management. Accreditation: PGEA and FFP applied for. Information: Dr Myra Holbrook, 20 Grange Close, Skelton, York YO30 1YR, UK. Tel: +44 (0) 1904 470674. E-mail: myra. holbrook@york.nhs.uk.

5 March 2005

Title: NW Society of Sexual Medicine and Family Planning Spring Meeting. Venue: Partnership for Learning Conference Centre, South Road, Liverpool, UK (near Speke Airport). Details: The topics for discussion are: (morning session) female sexual dysfunction, vulval problems, osteoporosis; (afternoon session) general scenarios provided by members and committee with some GUM/STI expert panel. Accreditation: FFP. Information: Mavis L Barnard, 7 Regent Road, Chorley PR7 2DH, UK. Tel: +44 (0) 1257267657 E-mail: mavis@ lilianbarnard.freeserve.co.uk.

14-18 March 2005

Title: Osteoporosis: A Practical Approach to Diagnosis and Clinical Management. Venue: Medical School, University of Warwick, Warwick, UK. Information: Guillermina Anorve-Galicia, Clinical Sciences, Medical School, University of Warwick CV4 7AL, UK. Tel: +44 (0) 2476522913. E-mail: G. Anorve-Galicia@warwick. ac.uk.

19 March 2005

Title. 'Hard to Reach.' Venue: Conference Centre, Stirling Royal Infirmary, Stirling, UK. Details: This meeting will focus on groups of people who access reproductive health care poorly. What are their special needs and what are the barriers to accessing reproductive health care? Accreditation FFP applied for. Information: Laura Brady, Dean Terrace Family Planning and Well Woman Clinic, 18 Dean Terrace, Edinburgh EH4 1NL, UK. Tel: +44 (0) 131315 4827. E-mail: laura.brady@ lpct.scot. nhs.uk.
11-13 April 2005, 27-29 June 2005 and throughout 2005

Title: FFPRHC Diploma in Family Planning and Reproductive Health Care Theoretical Courses. Venue: Liverpool Women's Hospital NHS Trust, Liverpool. UK. Details: A 2.5-day Facultyapproved theory course covering all six modules. Information: Mrs Carmel M Farrell (see 21 April 2005 entry).

\section{3-14 April 2005}

Title: STIF Course. Venue: Chancellor's Conference Centre, Manchester, UK. Details: The aim of the course is to equip participants with the basic knowledge, skills and attitudes for the effective management of STIs outside the GUM setting. Accreditation: FFP, RCN and BASHH Information: Irene Healey, 63-65 Palatine Road, Withington, Manchester M20 3LJ, UK. Tel: +44 (0) 161434 8629. Fax: +44 (0) 1614341889 E-mail: i.healey@man.ac.uk.

\section{April 2005}

Title: Update in Women's Health. Venue: Postgraduate Centre, Freeman Hospital, Newcastle-upon-Tyne, UK. Details: Open to all doctors and health care staff working in or with an interest in family planning and reproductive health care. Accreditation: PGEA and FFP (6 hours) applied for. Information: Dr Margaret Hogarth Newcastle Contraception \& Sexual Health Service, Graingerville Clinic, Newcastle General Hospital, Westgate Road, Newcastle-upon-Tyne NE4 6BE, UK. Tel: +44 (0) 191219 5239. Fax: +44 (0) 191 219 5232. E-mail: margaret.hogarth@newcastlepct.nhs.uk.

18-20 April 2005

Title: DFFP Basic Theory Course. Venue: London, UK. Details: A 3-day DFFP course suitable for doctors wishing to obtain the Diploma of the FFPRHC (of the RCOG). The course is also suitable for updating family planning doctors. Accreditation: FFP applied for. Information: Grace Gray, Training Administrator, The Sexual \& Reproductive Health Training Partnership, Southwark PCT, St Giles Hospital, St Giles Road, London SE5 7RN, UK. Tel: +44 (0) 2077713322. Fax: +44 (0) 207771 3338. E-mail: srhtp@ southwarkpct.nhs.uk.

\section{April 2005}

Title: Annual Doctors and Nurses Family Planning Update Day. Venue: Hanover International Hotel, Stretton, Warrington, UK. Details: A 1-day updating course covering a variety of interesting topics presented by leading specialists. Accreditation: FFP CME. This conference is also run in association with The Mersey Deanery. Information: Mrs Carmel M Farrell, Liverpool Women's Hospital NHS Trust, Mersey Region Group for Family Planning Training, 2nd Floor, Crown Street, Liverpoo L8 7SS, UK. Tel: +44 (0) 1517024102 E-mail: Carmel.Farrell@1wh-tr.nwest.nhs.uk.

\section{5-29 April 2005}

Title: Module 2: Reproductive Health in the Community. Venue: Medical School, University of Warwick, Warwick, UK. Information: Guillermin Anorve-Galicia, Clinical Sciences, Medical School, University of Warwick CV4 7AL, UK. Tel: +44 (0) 2476 522913. E-mail: G.Anorve-Galicia@ warwick.ac.uk

26-27 May 2005

Title: FFPRHC Annual Scientific Meeting. Details: See display advertisement on page 85.
27-29 June 2005

Title: DFFP Basic Theory Course. Venue London, UK. Details: A 3-day DFFP course suitable for doctors wishing to obtain the Diploma of the FFPRHC (of the RCOG). The course is also suitable for updating family planning doctors. Accreditation: FFP applied for. Information: Grace Gray, Training Administrator, The Sexual \& Reproductive Health Training Partnership, Southwark PCT, St Giles Hospital, St Giles Road, London SE5 7RN, UK. Tel: +44 (0) 2077713322 Fax: +44 (0) 207771 3338. E-mail: srhtp@southwarkpct.nhs.uk.

23-25 August 2005

Title: Women's Health \& Asian Traditional Medicine (WHAT Medicine). Venue: Kuala Lumpur Convention Centre, Kuala Lumpur, Malaysia. Details: Promoting complete health care for women, the conference will focus on Asian health traditions for women's health and wellbeing. Information: Mary George, Conference Secretary, WHAT Medicine 2005, 54 Jalan SS2/72, 47300 Petaling Jaya, Selangor, Malaysia. Tel: +603 7965 2702/7965 2729. Fax: +603 7965 2899/7965 2777. E-mail: mary@whatmedicine.org. Website: www.whatmedicine.org. Also see display advertisement on page 86 .

14-15 September 2005

Title: STIF Course. Venue: Chancellor's Conference Centre, Manchester, UK Details: The aim of the course is to equip participants with the basic knowledge, skills and attitudes for the effective management of STIs outside the GUM setting. Accreditation: FFP, RCN and BASHH. Information: Irene Healey, 63-65 Palatine Road, Withington, Manchester M20 3LJ, UK. Tel: +44 (0) 161434 8629. Fax: +44 (0) 1614341889 E-mail: i.healey@man.ac.uk.

12-15 October 2005

Title: 14th European Academy of Dermatology and Venereology Congress. Venue: The London ExCeL Exhibition Centre, London, UK. Details: The scientific programme will cover all the main topics in dermatology and venereology. Accreditation: CME accredited, recognised by the American Academy of Dermatology. Information: Chris Garrett. Tel: +44 (0) 207383 0266. Fax: +44 (0) 207388 0487. E-mail: eadv@bad.org.uk. Website: www.eadv2005.com.

\section{7-19 October 2005}

Title: DFFP Basic Theory Course. Venue: London, UK. Details: A 3-day DFFP course suitable for doctors wishing to obtain the Diploma of the FFPRHC (of the RCOG). The course is also suitable for updating family planning doctors. Accreditation: FFP applied for. Information: Grace Gray, Training Administrator, The Sexual \& Reproductive Health Training Partnership, Southwark PCT, St Giles Hospital, St Giles Road, London SE5 7RN, UK. Tel: +44 (0) 2077713322 Fax: +44 (0) $20 \quad 77713338$. E-mail: srhtp@southwarkpct.nhs.uk.

\section{1-15 February 2006}

Title: Siam Care's Conference. Details: See display advertisement on page 85 .

There is a charge of $\$ 50.00+$ VAT for each meeting/course publicised. For guaranteed inclusion in he submitted by 18 February 2005. For a boling fom pubmitted by 18 February 2005. For a booking form please contact Sarah Monger at PMH Publications, PO Box 100, Chichester, West Sussex PO18 8HD, UK Tel: +44 (0) 1243 576444. Fax: +44 (0) 1243567456 E-mail: sarah.monger@pmh.uk.com. 